\title{
Supplements and Foods with Potential Reduction of Blood Pressure in Prehypertensive and Hypertensive Subjects: A Systematic Review
}

\author{
Aline de Freitas Brito, ${ }^{1,2}$ Caio Victor Coutinho de Oliveira,,3 \\ Lydiane Tavares Toscano, ${ }^{2,3}$ and Alexandre Sérgio Silva ${ }^{1,2,4}$ \\ ${ }^{1}$ Department of Physical Education, Federal University of Paraíba, 58.051-900 João Pessoa, PB, Brazil \\ ${ }^{2}$ Research Laboratory for Physical Training Applied to Performance and Health, Federal University of Paraíba, \\ 58.051-900 João Pessoa, PB, Brazil \\ ${ }^{3}$ Department of Nutrition, Federal University of Paraíba, 58.051-900 João Pessoa, PB, Brazil \\ ${ }^{4}$ Instituição Federal University of Paraíba/Health Sciences Center Endereço: Campus I-Castelo Branco I, \\ 58.051-900 João Pessoa, PB, Brazil
}

Correspondence should be addressed to Alexandre Sérgio Silva; ass974@yahoo.com.br

Received 25 January 2013; Accepted 18 February 2013

Academic Editors: Y. Iwashima, K. Karatzi, H. Komine, and A. A. Noorbala

Copyright (C) 2013 Aline de Freitas Brito et al. This is an open access article distributed under the Creative Commons Attribution License, which permits unrestricted use, distribution, and reproduction in any medium, provided the original work is properly cited.

\begin{abstract}
Although the dietary approaches for stop hypertension (DASH) is well established and effective in reduction of blood pressure, in recent years, new scientific studies have indicated that specific food, nutrients isolated from foods, and even commercial food supplements are not covered by DASH. In this research, these nutrients were evaluated through a review using the databases of PubMed with the terms "dietary supplements and blood pressure" without a limit of date. Vitamins (C, D, and E) and minerals (potassium and copper) promote the greatest reductions in BP, around 7 to $14 \mathrm{mmHg}$ for systolic blood pressure (SBP) and 4 to $5 \mathrm{mmHg}$ for diastolic blood pressure (PAD). Antioxidants reduce SBP and DBP in 3 to $27 \mathrm{mmHg}$ and 3 to $4 \mathrm{mmHg}$, respectively. Among the amino acids, only L-arginine was effective in promoting reduction of 20 and $15 \mathrm{mmHg}$ for SBP and DBP, respectively. In food, the grape juice promoted the highest reductions in SBP and DBP, around $8 \mathrm{mmHg}$ and $6 \mathrm{mmHg}$, respectively. Finally, for commercial supplements, the fermented milk product $\mathrm{GAIO}^{\mathrm{R}}$, the grain salba, and fish oil promoted reductions of about 4,4; 6; and $5 \mathrm{mmHg}$ and 3,4; 3; and $1 \mathrm{mmHg}$ for SBP and DBP, respectively. Therefore, new nutrients, foods, and supplements can enrich the recommendations of the DASH.
\end{abstract}

\section{Introduction}

The degenerative diseases are the most prevalent in the world today, representing one of the greatest public health problems in the actuality [1]. According to estimates of the World Health Organization [2], these diseases are responsible for about $60 \%$ of all deaths worldwide, and $46 \%$ of the global burden of diseases affecting the population. Among them predominate obesity ( $12 \%$ of world population) [2], diabetes (10\% of world population) [3], and dyslipidemia (7.9\% of deaths worldwide) [2]. The main cause of these comorbidities have been the stress, sedentary lifestyle and eating habits.
All of these diseases are potentially able to promote increased blood pressure. While the fatty produced substances such as angiotensinogen and proinflammatory contribute to elevate blood pressure [4]; hyperlipidemia results in excessive oxidation of low density lipoproteins with subsequent atherosclerotic process [5]. The state of diabetes promotes strong oxidative stress that contributes unequivocally to endothelial dysfunction, inflammation, and vasoconstriction which increases blood pressure [6]. Therefore, these three states of morbidity are among the risk factors of hypertension that are, among all chronic diseases, the most prevalent, affecting about $30 \%$ of the world population [2], 


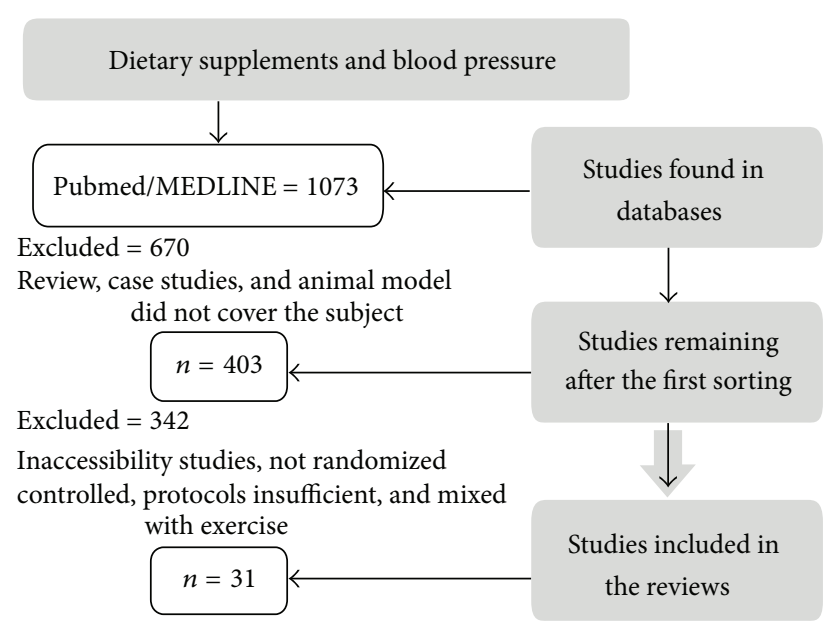

FIGURE 1: Organogram of activities to select articles.

and that causes the greatest financial expenditure on health in most countries of the world.

A healthy lifestyle with physical exercise, emotional stress management, and correct eating habits are the main factors that could be altered in order to prevent these diseases [7] and minimizing the resulting increase in blood pressure. In nutritional context, the DASH dietary pattern (dietary approaches to stop hypertension), which recommends a diet rich in fruits, vegetables, fiber, minerals, and dairy products low in fat, has an important impact on reducing BP [8, 9], in addition to enhancing weight loss, and reduction of cardiovascular risk biomarkers [10].

Despite the worldwide acceptance of the procedure DASH, recent research has provided new information about the hypotension effect of specific nutrients isolated from food (i.e., vitamins, minerals, amino acids, and antioxidants). Consequently, the industry has available supplementation on the market of a variety of nutritional supplements with proposed improvement cardiometabolic performance at the same time, a scientific research has evaluated the efficacy of these products in BP reduction. Additionally, other recent studies also suggest some new food as capable of promoting hypotensive action.

Therefore, this study is a systematic review conducted for the purpose of providing an update of the evidence available in the literature until the year 2012 about effectiveness of isolated nutrients extracted from food, nutritional supplements, and novel foods proposed to have the capacity to reduce blood pressure hypercholesterolemic, diabetic, and obese hypertensive patients.

\section{Methods}

The search for articles was performed systematically in PUBMED/MEDLINE (Medical Literature Analysis and Retrieval System Online) unlimited data and previous to the May 17, 2012, with both genders, also with no age limits. The studies were evaluated independently by three reviewers in a blinded way. Possible misunderstandings that arose were resolved by consensus between the reviewers.

We adopted the crossing of the descriptors: (1) dietary supplements and (2) blood pressure. We observed the occurrence of 1073 studies. Only randomized-controlled studies, conducted with human subjects, found that the influence of dietary supplementation on blood pressure reduction was considered. Based on this, first were eliminated through the titles and abstracts of studies that have used to compose your sample: animals, pregnant women, and patients with diseases hadn't cardiovascular risk. At this stage yet, studies of literature review and systematic review were also eliminated. In the second selection, through the full text longitudinal studies were excluded, those involving a group of volunteers to physical exercise, the experimental group who had normotensive subjects, studies without baseline or end-systolic and/or diastolic pressures in its results, and those who have not included subjects with cardiometabolic diseases that were not randomized controlled trials.

Thus, 31 articles met the criteria for composing the reference of this study. Figure 1 presents a detailed organization chart of the activities that were carried out to select articles. The selected studies were categorized according to the nutrient intake in the following categories: vitamins and minerals, antioxidant compounds, aminoacids, fresh food, and commercial supplements.

\section{Results and Discussion}

3.1. Quality Control Studies. Quality control was conducted by filling the criteria of scale present in PEDro.20. Only studies with methodological quality score of above three were included in this paper. Of the 31 studies chosen to compose the review, 22 received score of 10 , five note 9 , four notes 7 , and two studies only, received 8 and 5 , respectively.

3.2. Characteristics of Study Subjects. Of the 31 articles, 11 were conducted with hypertensive individuals, the majority with hypertension mild degree. In most studies, no subjects discontinued the use of antihypertensive medication during the research. Ten studies were conducted with type 2 diabetes, four with obese grade 1 based on BMI, five with hypercholesterolemia, and one with renal disease. These studies, the subjects of a group of diabetics, obese in another group, and another group of hypercholesterolemic, were concomitantly hypertensive. Blood pressure of the subjects of other studies was consistent with values of prehypertension (between 120 to 160 and 77 to $88 \mathrm{mmHg}$ for systolic and diastolic components of blood pressure). With respect to age, 21 trials were conducted with middle-aged subjects ( $40-58$ years) and 10 performed with elderly (60-70 years). Of these studies, 24 were conducted for both genders, six were with males and one with females. The main characteristics of several studies found are shown in Table 1.

3.3. Nutrients Investigated in Studies. Nutrients investigated in the selected articles were classified by us into vitamins and minerals, antioxidant compounds, proteins, or amino 


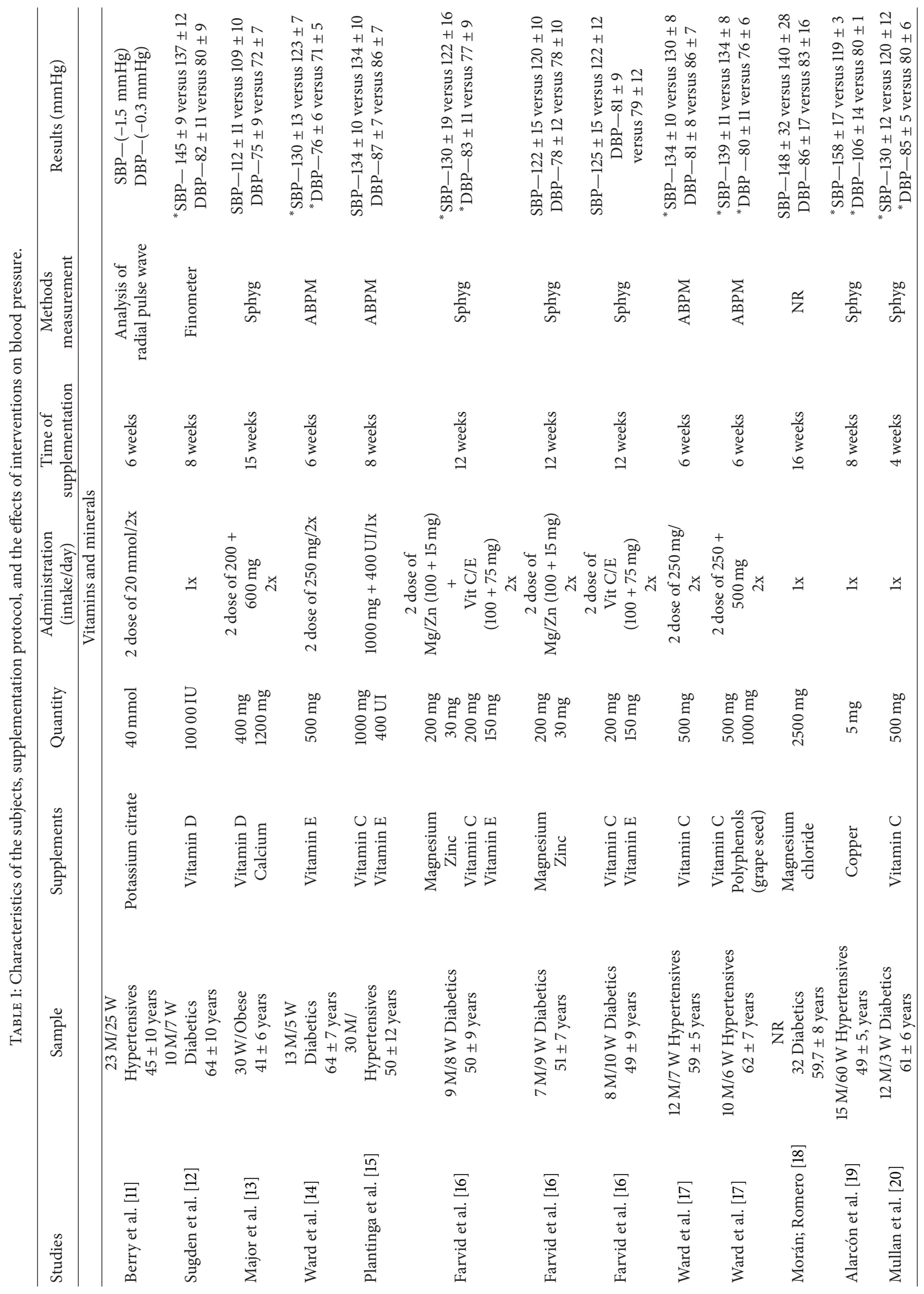




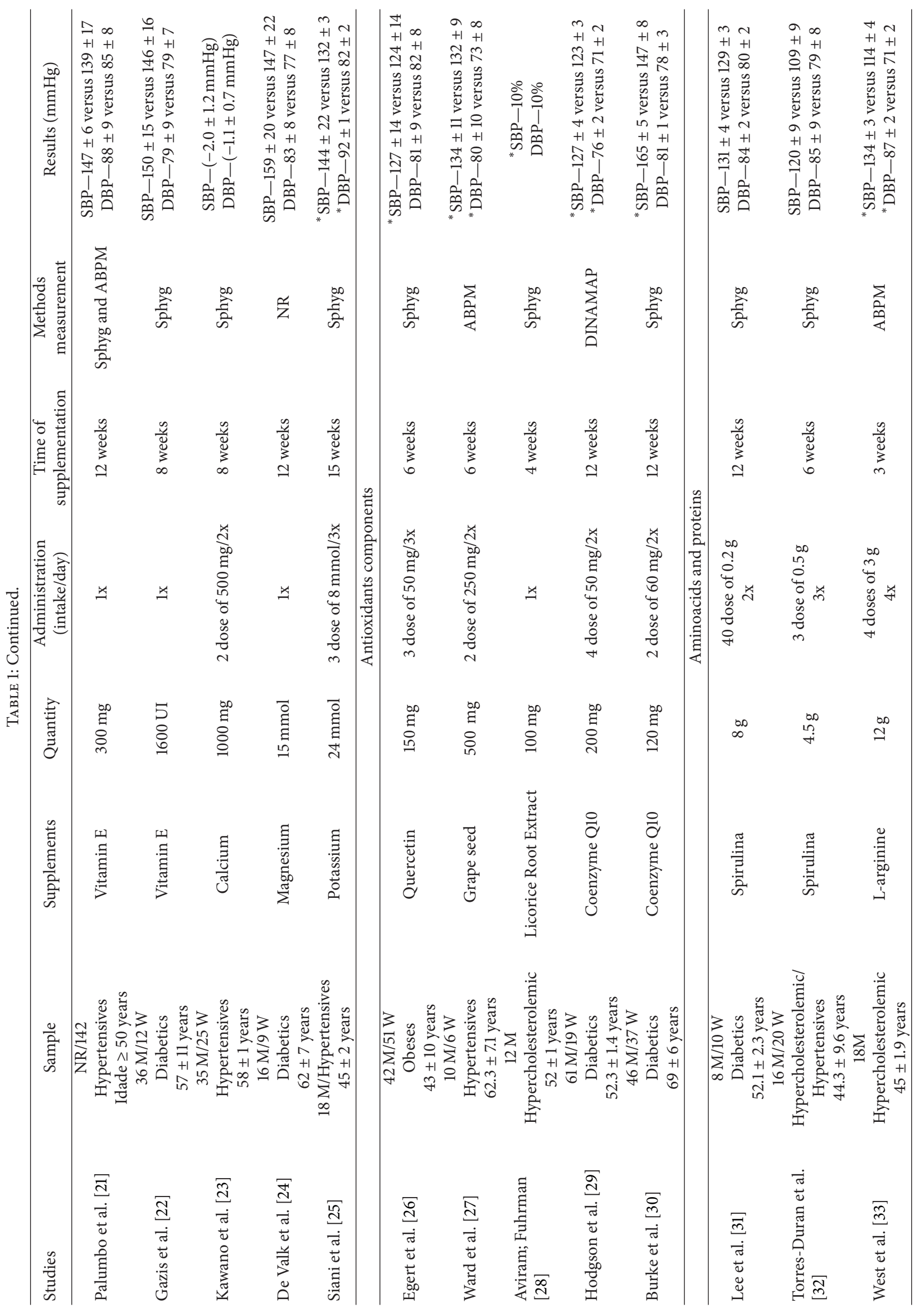




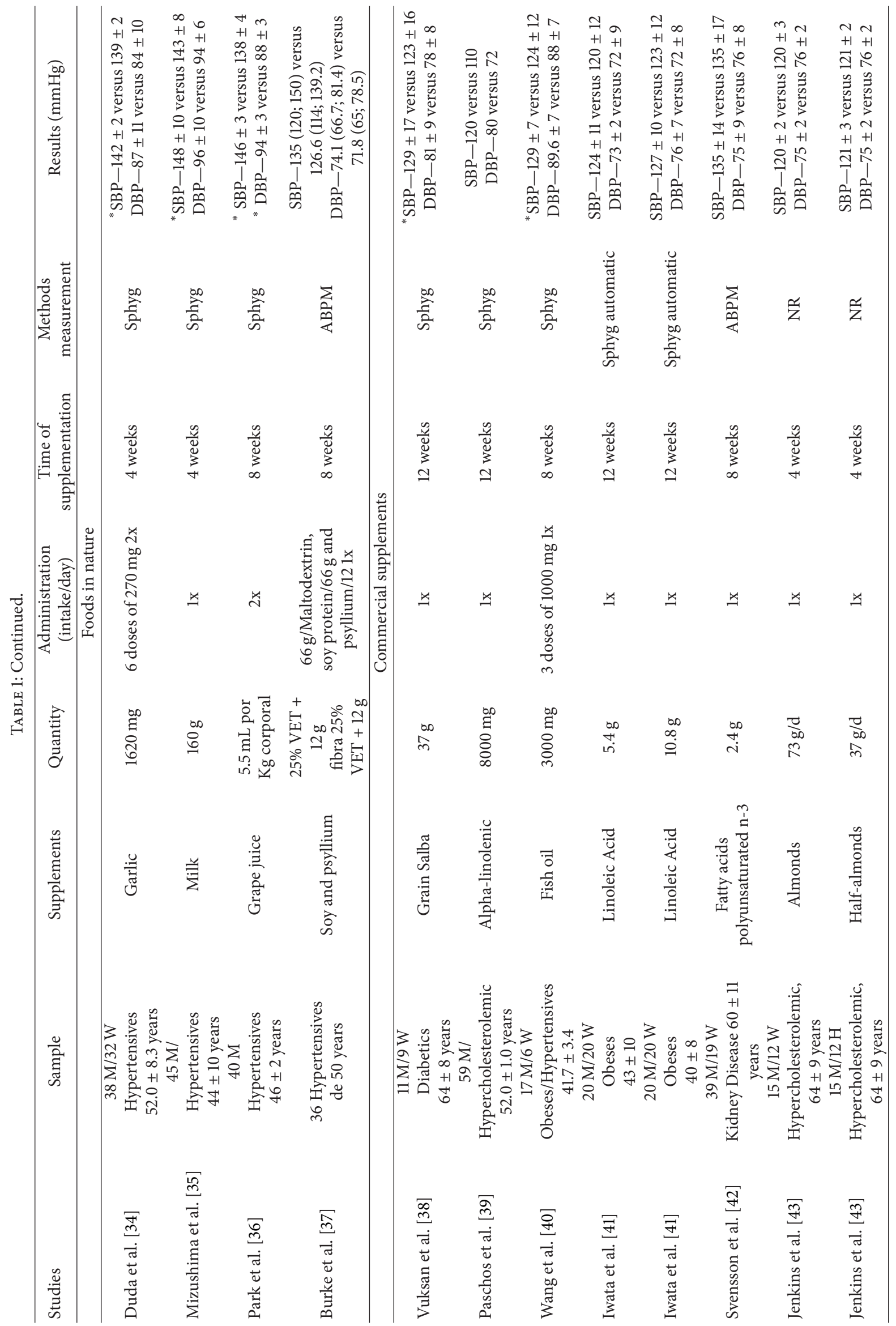




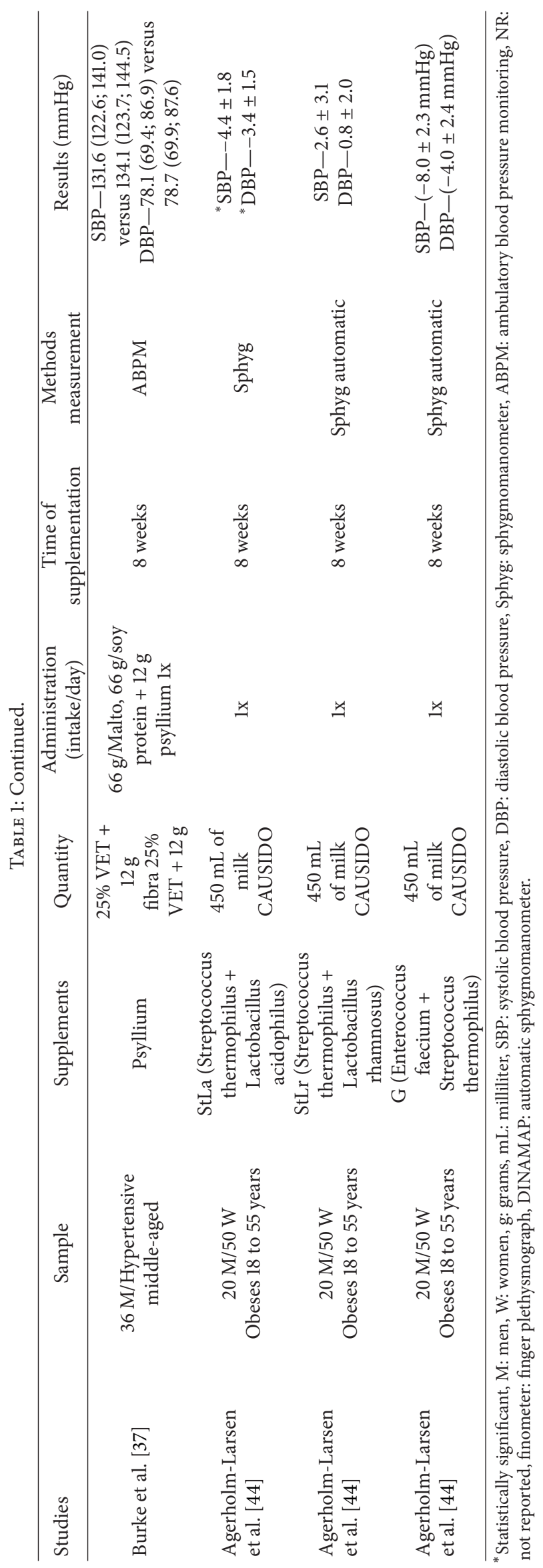


TABLE 2: Descriptive statistics for variables in supplementation.

\begin{tabular}{|c|c|c|c|c|}
\hline & Studies & Minimum & Maximum & Mode \\
\hline \multicolumn{5}{|c|}{ Vitamins and minerals } \\
\hline Dosage & 15 & 1 & 4 & $1 \mathrm{x}$ ao dia ( 8 studies) \\
\hline Supplementation time & 15 & 4 & 16 & 8 weeks (5 studies) \\
\hline Reduction in SBP & 15 & 2.0 & 12.0 & $8 \mathrm{mmHg}$ (2 studies) \\
\hline Reduction in DBP & 15 & 1.0 & 10.0 & $6 \mathrm{mmHg}$ (2 studies) \\
\hline \multicolumn{5}{|c|}{ Antioxidants components } \\
\hline Dosage & 5 & 1 & 3 & $2 \mathrm{x}$ ao dia (2 studies) \\
\hline Supplementation time & 5 & 4 & 12 & 6 weeks (2 studies) \\
\hline Reduction in SBP & 5 & 3.0 & 18.0 & $4 \mathrm{mmHg}$ (2 studies) \\
\hline Reduction in DBP & 5 & 5.0 & 7.0 & $4 \mathrm{mmHg}$ (2 studies) \\
\hline \multicolumn{5}{|c|}{ Aminoacids and proteins } \\
\hline Dosage & 3 & 1 & 4 & - \\
\hline Supplementation time & 3 & 3 & 12 & - \\
\hline Reduction in SBP & 3 & 1.0 & 10.0 & - \\
\hline Reduction in DBP & 3 & 3.0 & 6.0 & - \\
\hline \multicolumn{5}{|c|}{ Foods in nature } \\
\hline Dosage & 4 & 1 & 4 & 1x/day (2 studies) \\
\hline Supplementation time & 4 & 4 & 8 & 8 weeks ( 3 studies) \\
\hline Reduction in SBP & 4 & 3.0 & 15.0 & $8 \mathrm{mmHg}$ (2 studies) \\
\hline Reduction in DBP & 4 & 4.0 & 6.0 & $4 \mathrm{mmHg}$ (2 studies) \\
\hline \multicolumn{5}{|c|}{ Commercial supplements } \\
\hline Dosage & 13 & 1 & 3 & 1x/day (7 studies) \\
\hline Supplementation time & 8 & 4 & 12 & 6 weeks (5 studies) \\
\hline Reduction in SBP & 8 & 6.0 & 8.0 & $5 \mathrm{mmHg}$ ( 2 studies) \\
\hline Reduction in DBP & 13 & 4.0 & 8.0 & - \\
\hline
\end{tabular}

SBP: systolic blood pressure. DBP: diastolic blood pressure.

acids. We also found studies with fresh food and commercial supplements. Ten studies were conducted with vitamins and seven with minerals. Among the vitamins, the most used were vitamin $\mathrm{C}$ and vitamin E. For studies with minerals, wasn't observed a nutrient relapsing, so that potassium, calcium, magnesium, zinc, and copper minerals were investigated. For the five studies with antioxidants, three used flavonoids and two coenzyme Q10. Only three studies were selected in the category of aminoacids or proteins, two with spirulin, one with L-arginine and five with food in nature (soy, milk, grape juice, and garlic). With respect to commercial supplements, eight studies were selected to comprise this category, of which, oilseeds received six of these studies. The forms of nutrients are categorized in Table 1.

3.4. Protocols Studies. The interventions lasted three to twelve weeks, with administration performed one to four times daily, and five or seven days per week. The dosage of each product varies considerably in all categories in which nutrients were categorized. The more frequent form of BP measurement was auscultatory method, using apparatus type sphygmomanometer. Table 1 presents each of the selected studies, showing the characteristics of the subjects, supplementation protocol, how to measure blood pressure, and the effects of nutritional interventions on blood pressure. Meanwhile,
Table 2 shows a summary of Table 1, which presents the highest and lowest blood pressure reductions, as well as the mode for each of the categories in which the nutrients are categorized.

3.5. Vitamins and Minerals. Evidence support an inverse relationship between vitamin intake and cardiovascular events [45-47]. In fact, the therapeutic use of some vitamins minimizes the risk of atherosclerotic plaque formation and its main determinants [48]. Meanwhile, the minerals are involved in almost all metabolic pathways in the body and play an important role in the treatment of cardiovascular diseases and their risk factors [16].

Among the vitamins, $\mathrm{C}$ and $\mathrm{E}$ are the most studied from the standpoint antioxidants and enzyme, besides being nutrients with potential biological functions [49]. In this paper [14-17, 20-22], studied collected showed the consumption of vitamins $\mathrm{C}$ and $\mathrm{E}$ as probable lowering of blood pressure.

Mullan et al. [20] observed that a $500 \mathrm{mg}$ dose/day of vitamin $\mathrm{C}$ for four weeks was able to reduce SBP $(10 \mathrm{mmHg})$ DBP ( $4 \mathrm{mmHg}$ ) in diabetic subjects. When the same amount was administered daily in hypertensive subjects, supplementation decreased the SBP for only $4 \mathrm{mmHg}$ [17]. Another group studied by these authors was treated with the same 
amount of vitamin C enriched with $1000 \mathrm{mg} /$ day of polyphenols $(1000 \mathrm{mg} / \mathrm{d})$ grape seeds, and the hypotensive effect was potentiated in both SBP $(5 \pm 11 \mathrm{mmHg})$ and for DBP $(4 \pm 11 \mathrm{mmHg})$. Moreover, the study of Plantinga et al. [15], the amount of dietary intake of vitamin $C$ was the double (1000 mg) and, associated with vitamin E (400 IU), however, BP reduction did not occur in hypertensive subjects. Similarly, a combination of vitamin C $(200 \mathrm{mg} / \mathrm{d})$ and $\mathrm{E}$ $(150 \mathrm{mg} / \mathrm{d})$ also was not effective in reducing blood pressure in diabetic subjects [16].

Some studies corroborate findings of this paper pointing to a reduction in blood pressure from the consumption of vitamin C $[50,51]$ in hypertensive patients. Duffy et al. [51] evaluated $500 \mathrm{mg} /$ day of vitamin $\mathrm{C}$ in hypertensive patients for four weeks and observed a reduction in SBP of $13 \mathrm{mmHg}$, but not in DBP. Fotherby et al. [50] also using the same protocol intake in hypertensive patients, for a period of 12 weeks and an observed reduction of $3 \mathrm{mmHg}$ in SBP, however, DBP remained unchanged. A long period of intake of vitamin $\mathrm{C}$ may be needed to obtain vasodilatation and consequently reduce blood pressure $[52,53]$. However, evidence from human studies are not sufficient to determine the ideal timeconsuming vitamins to lower blood pressure without possible adverse effects [54].

Supplementation of vitamin E $(500 \mathrm{mg} / \mathrm{d})$ for six weeks was effective in reducing SBP $(7 \mathrm{mmHg})$ and $\mathrm{DBP}(5 \mathrm{mmHg})$ in diabetic patients [14]. In contrast, the consumption of vitamin E (1600 IU/d), for eight weeks, did not cause changes in pressure values in diabetic [22] as well as in hypertensive patients who consumed controlled $300 \mathrm{mg} / \mathrm{d}$ during 12 weeks, having no significant effect on BP [21]. This result corroborates other studies that evaluated the chronic effects of vitamin $\mathrm{E}$ in blood pressure $[55,56]$ using the same dose $(300 \mathrm{mg} / \mathrm{d})$ in people with cardiovascular risks. Gazis et al. [22] found a significant reduction in SBP in hypertensive patients when a doubled $(600 \mathrm{mg} / \mathrm{d})$ dose is administered. This fact suggests that a higher dose of vitamin E, however, within the values recommended daily, may possibly be more effective.

Vitamins C (hydrophilic antioxidant) and E (lipophilic antioxidant) act through nonenzymatic system in the prevention and capture of reactive oxygen species (ROSs), generated by vascular cells [57]. The redox imbalance of hypertension often leads to functional alterations mediated by angiotensin II, stimulating the enzyme NADPH oxidase to increase the production of superoxide anion radical $\left(\mathrm{O}_{2}^{-\bullet}\right)$, favoring the buffer nitric oxide $\left(\mathrm{NO}^{\bullet}\right)$ action to oxidative stress, detriment its vasodilator function [57]. However, it is unclear whether the intake of these vitamins may influence the antioxidant activity and enzyme cofactor, and how you can help prevent the formation of ROS [58, 59].

Evidence suggests that vitamin D may also improve cardiometabolic profile, reducing the risk factors associated $[60,61]$. In this paper, some studies were pooled studies of vitamin $\mathrm{D}$ addressing this perspective $[12,13]$. In the study of Sugden et al. [12] oral dose (100000 IU/day) of vitamin D was used for eight weeks, which has been shown to decrease significantly the systolic blood pressure by $14 \mathrm{mmHg}$, improving endothelial function in patients with type 2 diabetes and deficiency of vitamin $\mathrm{D}$. This can be explained via the renin-angiotensin system and vascular function, where the first hydroxylase-1- $\alpha$ enzyme metabolite converting of vitamin $\mathrm{D}\left(25[\mathrm{OH}] \mathrm{D}\right.$ to $\left.1,25[\mathrm{OH}]_{2} \mathrm{D} 3\right)$ acts as a binder for the nuclear transcription factor, regulating cell function in tissues such as endothelial cells and vascular smooth muscle, and thereby reducing blood pressure levels [62]. In contrast, when obese women were supplemented with vitamin D (400 mg/d) combined with calcium (1200 mg/d), they showed no improvement in cardiometabolic profile [13]. The low dose compared with the study of Sugden et al. [12] may explain these results.

Anyway, the current data allow to infer that there is no consensus that vitamins are really effective in reducing blood pressure. The lack of a conclusion is given by the fact that prospective studies and intervention in humans that prove the effectiveness of vitamin $\mathrm{D}$ in the prevention and treatment of cardiometabolic diseases are scarce. The researches that explain the exact mechanisms, by which the active form $\left(1,25[\mathrm{OH}]_{2} \mathrm{D} 3\right)$ improves $\beta$-cell function, the reninangiotensin system, and regulation, are also inconclusive.

Zinc, magnesium [16, 24], copper [19], potassium [11, $25]$, and calcium $[13,23]$ have been adopted in research, hypothesizing its hypotensive effect. Farvid et al. [16] showed that 12 weeks of consumption of $200 \mathrm{mg}$ of magnesium and $30 \mathrm{mg}$ of zinc supplementation did not reduce blood pressure in diabetic subjects. Magnesium and zinc, when enriched with vitamin C $200 \mathrm{mg}$ and $150 \mathrm{mg}$ vitamin E, promoted a significant reduction in the levels of PAS $(8 \mathrm{mmHg})$ and diastolic $(6 \mathrm{mmHg})$ in the same population [16]. Therefore, we cannot establish from this study, the efficacy of these minerals in reducing $\mathrm{BP}$, because only when associated with the vitamin $\mathrm{C}$ and $\mathrm{E}$, they were able to reduce blood pressure levels in diabetics. The solution of magnesium chloride when applied to diabetics for a period of 16 weeks also did not modify the blood pressure values [18]. Corroborating this finding, De Valk et al. [24] observed that magnesium supplementation $(15 \mathrm{mmol} / \mathrm{d})$ for 12 weeks, in diabetic patients, did not alter the blood pressure values. Therefore, there is no evidence that zinc and magnesiummay be able to promote BP reduction.

Consumption of potassium $(24 \mathrm{mmol})$ in hypertensive men, over a period of 15 weeks, decreased the SBP by $10 \mathrm{mmHg}$ and DBP by $7 \mathrm{mmHg}$ [25]. Several mechanisms have been proposed to explain the antihypertensive effect of a high intake of potassium, including an increased loss of water and sodium, suppression of secretion of renin and angiotensin, and stimulation of the activity of sodiumpotassium pump. However, Berry et al. [11] found no change in blood pressure after administration of $40 \mathrm{mmol}$ of potassium in hypertensive subjects for six weeks. Alarcón et al. [19] demonstrated that administration of another mineral, copper (5 mg/day), significantly decreased the SBP levels ( $r=$ $0.963)$ and DBP $(r=0.981)$ in treated hypertensive patients. Some studies show that cardiometabolic protective effect of minerals was not observed in blood pressure values during supplementation of calcium $(1000 \mathrm{mg} / \mathrm{d})$ for eight weeks in hypertensive subjects [23], even when that $(1200 \mathrm{mg} / \mathrm{d})$ was associated with vitamin D (400 mg/d), supplementing obese women for 15 weeks [13]. 
Based on these data, it can be stated that there is strong evidence linking vitamins to hypotensive effect, however, there is still no consensus that the minerals are effective in reducing blood pressure.

3.6. Antioxidants Compounds. Oxidative stress contributes to increase blood pressure by acting on eNOS uncoupling and decrease bioavailability of nitric oxide [63]. The result is a predominant on factors vasoconstrictors and low action of vasodilators in vascular bed [63]. In the cardiovascular system, the reactive oxygen species (ROSs) are produced in vascular cells by a number of oxidases, including NADPH oxidase, xanthine oxidase, lipoxygenase, and cytochrome P450 [63, 64]. Furthermore, clinical data have suggested that there is increased endogenous antioxidant, introducing exogenous antioxidants present in food. In fact, the reduction of oxidative stress has been accompanied by decreasing cardiovascular risk and blood pressure in humans [65-70].

Antioxidants commonly used include vitamins A, C, and E, L-arginine, flavonoids, coenzyme Q10, and alpha-lipoic acid $[64,71]$. Of these, flavonoids have gained attention for their higher antioxidant power than the others (Ross and Kasum). These phenolic compounds are commonly found in high concentrations in many fruits, vegetables, and beverages, including apples, strawberries, grapes, onions, pomegranate, red wine, tea, cocoa, and dark chocolate [72].

In fact, the selected studies that used supplements based on flavonoids, all demonstrated significant reductions in blood pressure in hypertensive [27], obese [26], and hypercholesterolemic individuals [28]. The reductions were more pronounced for systolic blood pressure, with a reduction of around $3 \mathrm{mmHg}$. For diastolic blood pressure, only the study by Ward et al., [27] identified a significant reduction ( $3 \mathrm{mmHg}$ ). Interestingly, in this study, the doses of flavonoids were much higher (500 mg versus $150 \mathrm{mg}$ in the others). Although these reductions are relatively discreet, these are clinically significant, so that hypotension afforded by the flavonoid is equivalent to the use of a class of antihypertensive medication [73].

In addition to flavonoids, another supplement with strong action antioxidant is coenzyme Q10. Molecule lipid soluble, derived mainly from endogenous synthesis, plays an essential role as the carrier of electrostatic mitochondrial oxidative phosphorylation [74] . The studies of this paper involving the use of coenzyme Q10 [29, 30] were performed with diabetic subjects and also identified significant reductions in blood pressure of $4 \mathrm{mmHg}$ [30] and $27 \mathrm{mmHg}$ [29]. Hodgson et al. [29] found a reduction of $4 \mathrm{mmHg}$ diastolic. Interestingly, the study showed that diastolic hypotension, as well as flavonoids, was also performed with larger amount of coenzyme Q10 against the others (200 versus $60 \mathrm{mg}$ ), which enables to infer that the reduced pressure in response to supplementation with antioxidants appears to be dependent on the concentration.

The mechanism of cell signaling by flavonoids give up buffering of ROS (Ross and Kasum) or limits its formation [69]. The actions of the polyphenols as buffering occurs through their ability to modulate the levels of activity of nitric oxide synthase (eNOS) and, therefore, the bioavailability of endothelial nitric oxide (NO) [75-79]. The flavonoids reduce the formation through interaction with inhibitory kinase signaling pathways, such as via the PI3-kinase/Akt and intracellular $\mathrm{Ca}^{2+}[80,81]$, and promote inhibition of the enzyme NADPH oxidase, which is the enzyme responsible for the production of ROS. Furthermore, prevents vascular injury by inhibition of MAPK inhibition of transcription factors (NF-kB), and matrix metalloproteinases (MMP), allowing reduction in angiogenesis, migration and proliferation of vascular cells.

It is well established that the flavonoids inhibit the oxidation of low density lipoprotein (LDL) [82] to reduce the formation of atherosclerotic lesions [83], inhibit platelet aggregation [83], decrease expression of vascular cell adhesion molecule [84], and reduce blood pressure or prevent its rise [85].

3.7. Aminoacids and Proteins. Some isolated nutrients of food have been investigated on possible hypotensive effect in individuals with cardiometabolic risk. Among those selected in this paper, proteins $[31,32]$ and amino acids were observed [33]. These nutrients are positively associated with the control of metabolic disorders (e.g., hypertension) [86, 87]. Spirulina has a high protein content and is considered one of the richest sources of vitamins and minerals, besides presenting phenolic compounds and essential fatty acids [88]. Furthermore, the research shows its various biological activities, among them is the vasodilator, proposing its antihypertensive action [89] as well as improved glycemic profile [90].

Torres-Duran et al. [32] studied the effects of oral supplementation of spirulina $4.5 \mathrm{~g} / \mathrm{d}$ in hypertensive and dyslipidemic subjects for six weeks and noted a reduction in SBP $(120 \pm 9$ versus $109 \pm 9 \mathrm{mmHg})$ and DBP $(85 \pm 9$ versus $79 \pm 8 \mathrm{mmHg}$ ), being observed since the fourth week of intervention. Corroborating this study, Lee et al. [31] also observed a significant reduction in DBP $(84 \pm 2$ versus $79 \pm$ $2 \mathrm{mmHg}$ ) when diabetic patients consumed $8 \mathrm{~g} / \mathrm{d}$ of spirulina for 12 weeks, however, the SBP remained unchanged.

According to Hsiao et al. [91], hypotension can be explained by vasodilation determined by an increase in nitric oxide synthesis, by inhibition of platelet aggregation, by inhibiting calcium mobilization, and by mediating the release of free radicals. Guan et al. [86] proposed that the high concentration of potassium and the low sodium content of spirulina would be able to generate positive implications PA, supported by a classic effect that food mediate several steps in the process of inflammation reducing atherothrombotic plaque formation. Based on these data, we can say that spirulina acts favorably on serum lipids, antioxidant capacity, and inflammatory response in diabetic, hypertensive, and dyslipidemic subjects. However, the mechanisms by which spirulina lowers blood pressure are not well understood.

Among the observed amino acid L-arginine is an amino acid which proposes to improve endothelial function contributing to the hypotensive effect from the synthesis of nitric oxide (NO) $[92,93]$. Additionally, other benefits such as improved blood flow and reduction in platelet aggregation have been attributed to L-arginine in human models [87]. West et al. [33], after oral intervention $12 \mathrm{~g} / \mathrm{d}$ of L-arginine 
in hypercholesterolemic men for three weeks, observed a reduction in SBP $(134 \pm 3$ versus $114 \pm 4)$ and DBP $(87 \pm$ 2 versus $71 \pm 2$ ), suggesting that $L$-arginine is involved in the mechanisms hemodynamic of hypotension. In fact, One mechanism that may explain these data is related to endothelial function [94]. The increase in plasma nitrite reflects an improvement in endothelial function and may explain the significant reduction of baseline blood pressure.

3.8. Foods in Nature. Despite that studies have demonstrated the efficacy of isolated nutrients (i.e., vitamins, minerals, and flavonoids) $[16,20]$ in reducing blood pressure, studies evaluating the effects of food in nature on blood pressure of hypertensive patients are scarce. Methodological difficulties and the impossibility of determining which particular food component is the active compound are some of the likely factors that may explain this paucity in the literature. Moreover, studies within natural food have the advantage of external validity, approaching more to the reality of population's eating habits and how these habits result in the proposed benefits in the studies.

Among the studies selected in this paper, we have investigated the effects of garlic [34], grape juice [36], and whey [35], all in hypertensive middle-aged people. While the wine had been well investigated, this paper found only studies with normotensive, which was an exclusion criterion at the time of selection of papers.

Dhawan and Jain [95] and Durak et al. [96] found that administration of garlic preparations resulted in significant reductions in blood pressure in hypertensive patients. The first garlic supplementation for eight weeks was able to reduce blood pressure in young hypertensive subjects. The latter, supplementing hypercholesterolemic patients for 16 weeks, found a significant decrease of systolic blood pressure around $22 \mathrm{mmHg}$. In contrast, Duda et al. [34] observed that the use of aged garlic extract, containing $1.62 \mathrm{mg}$ of allicin/day, resulted in modest reduction in blood pressure both systolic and diastolic blood pressure (about $1 \mathrm{mmHg}$ for both systolic and diastolic) without statistical differences. These results corroborate the findings of Brace [97], where they found no effect of preparations containing garlic on blood pressure.

Some factors may explain this discrepancy in the results. Among them is the duration of administration and the dosage used. In their study, Duda et al. [34], $1.62 \mathrm{mg}$ of allicin was administered for 4 weeks, while in studies of Dhawan and Jain [95] and Durak et al. [96] doses of $250 \mathrm{mg}$ and $10 \mathrm{~g}$ were administered, during 2 and 4 months, respectively.

Among compounds present in garlic, allicin is involved in most of the therapeutic benefits promoted by this food [98]. The benefits include reduction of low density lipoprotein cholesterol (LDL) and elimination of reactive oxygen species [98]. Warshafsky et al. [99] found that the consumption of 1-1.5 garlic cloves daily (containing approximately $1.5 \mathrm{mg}$ of allicin) can reduce cholesterol around 9\%. Likewise, [34] found a reduction in total cholesterol of around 9\%, despite not finding lower blood pressure in his study.

Therefore, the data of this paper support the premise that the incorporation of consumption of garlic compounds or derivatives have beneficial effects such as reduction of oxidative stress and lipid peroxidation in hypertensive subjects. For these benefits to be extended, it appears that the consumer must take chronically (at least 2 months) a minimum amount of allicin $250 \mathrm{mg}$ /day (about 2.5 garlic cloves).

The contained polyphenols in purple grape, red wine, and other dark red to purple color fruits are compounds with protective properties of the cardiovascular system since they increase the plasma concentration of high density lipoproteins (HDLs), slow the development of atherosclerosis, function as potent antioxidants, improve endothelial function, and are able to reduce blood pressure in hypertensive subjects [100]. The improvement of endothelial function would be due to the stimulation of increased production of nitric oxide by the vascular endothelium. This vessel has relaxants and antiaggregatory properties and in the long term can modulate the expression of protective genes of the cardiovascular system [101]. Studies with polyphenols isolated from foods are conclusive in demonstrating their cardiovascular protective effects, including lowering blood pressure.

Considering these effects for isolated polyphenols, Park et al. [36] investigated whether the ingestion of these nutrients contained in foods, grape juice, would be able to decrease blood pressure. They tested the hypothesis that chronic consumption (8 weeks) would reduce blood pressure via increased availability of nitric oxide. They observed a $9 \%$ reduction in systolic blood pressure (around $-7.2 \mathrm{mmHg}$ ) and diastolic (around $-6.2 \mathrm{mmHg}$ ), confirming Opie and Lecour [100]. However, the author proposes increase in NO production for explaining the hypotensive effect but does not have any data that supporting this idea.

Its important to note that the consumption of grape juice in the study of Park et al. [36] gave an average $881.14 \mathrm{mg} /$ day of flavonoids, whereas in these studies from isolated nutrients it was $500 \mathrm{mg}$ [26-28]. This corroborates the ability of grape juice (being consumed daily around $425.6 \mathrm{~mL}$ ) to promote beneficial effects on blood pressure and great applicability to the general population. Therefore, the inclusion of grape juice in the diet, even in low amounts, is an interesting strategy of eating habits to lower BP.

The potassium and calcium supplementation has been suggested as modulators of systemic arterial pressure [35]. The fermented skim-milk, Calpis sour milk, can serve as a nutritional strategy to control hypertension, since, besides possessing these nutrients, it has certain strains of bacteria, such as Lactobacillus helveticus and Saccharomyces cerevisiae, which has been shown to promote antihypertensive effect in SHR rats [102]. Additionally, this milk peptide fractions (valine-proline-proline and isoleucine-proline-proline) would be responsible for ACE inhibition, key enzyme in the pathophysiology of hypertension.

Based on this, Mizushima et al. [35] tested the hypothesis that consumption of this beverage $(160 \mathrm{~g} / \mathrm{dia})$ for 4 weeks would be sufficient to reduce blood pressure, in hypertensive subjects, about $-5 \mathrm{mmHg}$ and $2 \mathrm{mmHg}$, in systolic blood pressure, and diastolic respectively.

Although not proven in humans, the peptide fractions of the milk (valine and proline-proline-isoleucine-prolineproline) has the ability to inhibit ACE activity in SHR rats 
[102]. If this inhibitory effect is extended to humans is unclear [35]. It is proposed that these compounds in Calpis sour-milk (at doses of 0.033 and $0.025 \mathrm{~mL} / \mathrm{kg}$, resp.) have pharmacological activity sufficient for inhibition of the ACE activity and contribute to reducing pressure levels.

Because it contains a high concentration of $\mathrm{Ca}$, this nutrient could be considered responsible for blood pressure reductions observed in this study. However, the [Ca] was similar between the placebo and treatment groups, making it impossible to draw a cause-effect relationship for this particular nutrient. Furthermore, the [Ca] in the milk would be well below what is needed (about $90 \mathrm{mg}$ ) to promote positive effects as observed in other studies when used in isolation $(1000 \mathrm{mg})$ [103].

In short, it is interesting to note that the daily intake of 2.5 cloves of garlic, about $385 \mathrm{~mL}$ of grape juice, and $160 \mathrm{~g}$ of Calpis sour-milk can promote significant reductions in blood pressure. It should be noted that the amount of feed required to ensure hypotensive effect is so small that it can be easily implemented in the diet even by persons who may not display any of these taste in the food. Additionally, although it was not contemplated by the inclusion criteria, recent studies have shown that eating $100 \mathrm{~g}$ of dark chocolate [104] and $6 \mathrm{~g}$ of watermelon extract [105] were also able to promote $\mathrm{BP}$ reduction, may attenuate up to between $11.9 \pm 7.7$ and $-15.1 \pm 2.8 \mathrm{mmHg}$ for SBP.

3.9. Commercial Supplements. Dietary supplements are products added to the diet, which contain at least one of the following ingredients: vitamins, minerals, amino acids, proteins, metabolites, antioxidants, carbohydrates, lipids, fatty acids, or a combination of any of these [106]. Historically, dietary supplements have a wide acceptance and use by exercise practitioners, believing these products improve their sports performance and health [107].

Concomitant to the advancement and dissemination of information in the area of nutrition, the market potential of these products to other niche market products has grown rapidly. In this context, products intended for the general population, and specifically for hypertensive and cardiac subjects, began to have its production increased. However, these products are not always grounded in reliable scientific findings, often occurring in misinterpretation of results.

Among the selected studies by this paper, it was observed that the responsible components for the modulation of blood pressure were dietary fiber products, probiotics, and antioxidant compounds [30,38, 40, 41, 43, 44].

Vuksan et al. [38] verified the effectiveness of chia supplement on cardiovascular diseases markers. Despite finding satisfactory results (chia consumption of $37 \mathrm{~g} / \mathrm{d}$ for 12 weeks resulted in about $-6 \mathrm{mmHg}$ and $-3 \mathrm{mmHg}$ for systolic and diastolic blood pressure, resp.) it is not yet possible to draw firm conclusions because of the study's limitations. Among them, it is not known which of the various components of the product would be responsible for the positive effects, and it is unknown whether the effects of positive pressure of this food consumption were associated with direct consumption of chia or by changes in diet composition between treatments (intervention versus placebo).
As in the case of chia, there is no body of evidence linking the essential fatty acid supplementation or consumption of fermented milk CAUSIDO with lower blood pressure in hypertensive subject. Despite the remarkable relationship between fish consumption (source of essential fatty acids) and improvement in cardiovascular health, there is insufficient evidence to assert that supplementation of this type of product shows the same physiological effects.

In short, despite the growing interest and use of dietary supplements for blood pressure control, it is necessary to observe if there is a body of evidence in the specific literature to justify the use of these compounds for hypertension.

\section{Conclusion and Perspectives}

There is scientific evidence to support the idea that there is a reasonable variety of foods or isolated foods nutrients capable of promoting reduction of blood pressure in hypertensive, obese, diabetic, and hypercholesterolemic subjects. Interestingly, the magnitude of the blood pressure reduction is equivalent, in some cases, it is obtained by pharmacological agents. Some food and nutrients studied are already included in the DASH protocol, but others had their antihypertensive properties revealed only recently. Therefore, this paper provides subsidies to propose range of foods and nutrients that can be incorporated into the diet of people that need care for blood pressure and may provide a basis for future updates in DASH protocol.

\section{References}

[1] M. C. Lewicki, P. G. Kerr, and K. R. Polkinghorne, "Blood pressure and blood volume: acute and chronic considerations in hemodialysis," Seminars in Dialysis, vol. 26, no. 1, pp. 62-72, 2013.

[2] World Health Organization (WHO), "Obesity and overweight. Disponível," Fact Sheet 311, 2012, http://www.who.int/ mediacentre/factsheets/fs311/en/.

[3] American Diabetes Association, "Third-party reimbursement for diabetes care, self-management education, and supplies," Diabetes Care, vol. 26, 1, pp. S143-S144, 2003.

[4] D. R. Velez, M. Guruju, G. Vinukonda, A. Prater, A. Kumar, and S. M. Williams, "Angiotensinogen promoter sequence variants in essential hypertension," The American Journal of Hypertension, vol. 19, no. 12, pp. 1278-1285, 2006.

[5] Y. Yasunobu, K. Hayashi, T. Shingu, T. Yamagata, G. Kajiyama, and M. Kambe, "Coronary atherosclerosis and oxidative stress as reflected by autoantibodies against oxidized low-density lipoprotein and oxysterols," Atherosclerosis, vol. 155, no. 2, pp. 445-453, 2001.

[6] M. T. Schram, N. Chaturvedi, C. Schalkwijk et al., "Vascular risk factors and markers of endothelial function as determinants of inflammatory markers in type 1 diabetes: the EURODIAB prospective complications study," Diabetes Care, vol. 26, no. 7, pp. 2165-2173, 2003.

[7] L. F. Masson, G. McNeill, and A. Avenell, "Genetic variation and the lipid response to dietary intervention: a systematic review," The American Journal of Clinical Nutrition, vol. 77, no. 5, pp. 1098-1111, 2003. 
[8] L. P. Svetkey, T. J. Moore, D. G. Simons-Morton et al., "Angiotensinogen genotype and blood pressure response in the Dietary Approaches to Stop Hypertension (DASH) study," Journal of Hypertension, vol. 19, no. 11, pp. 1949-1956, 2001.

[9] P. R. Conlin, D. Chow, E. R. Miller III et al., "The effect of dietary patterns on blood pressure control in hypertensive patients: results from the Dietary Approaches to Stop Hypertension (DASH) trial," The American Journal of Hypertension, vol. 13, no. 9, pp. 949-955, 2000.

[10] J. A. Blumenthal, M. A. Babyak, A. Hinderliter et al., "Effects of the DASH diet alone and in combination with exercise and weight loss on blood pressure and cardiovascular biomarkers in men and women with high blood pressure: the ENCORE study," Archives of Internal Medicine, vol. 170, no. 2, pp. 126-135, 2010.

[11] S. E. Berry, U. Z. Mulla, P. J. Chowienczyk, and T. A. B. Sanders, "Increased potassium intake from fruit and vegetables or supplements does not lower blood pressure or improve vascular function in UK men and women with early hypertension: a randomised controlled trial," The British Journal of Nutrition, vol. 104, no. 12, pp. 1839-1847, 2010.

[12] J. A. Sugden, J. I. Davies, M. D. Witham, A. D. Morris, and A. D. Struthers, "Vitamin D improves endothelial function in patients with Type 2 diabetes mellitus and low vitamin D levels," Diabetic Medicine, vol. 25, no. 3, pp. 320-325, 2008.

[13] G. C. Major, F. Alarie, J. Doré, S. Phouttama, and A. Tremblay, "Supplementation with calcium + vitamin D enhances the beneficial effect of weight loss on plasma lipid and lipoprotein concentrations," The American Journal of Clinical Nutrition, vol. 85, no. 1, pp. 54-59, 2007.

[14] N. C. Ward, J. H. Wu, M. W. Clarke et al., "The effect of vitamin E on blood pressure in individuals with type 2 diabetes: a randomized, double-blind, placebo-controlled trial," Journal of Hypertension, vol. 25, no. 1, pp. 227-234, 2007.

[15] Y. Plantinga, L. Ghiadoni, A. Magagna et al., "Supplementation with vitamins $C$ and $E$ improves arterial stiffness and endothelial function in essential hypertensive patients," The American Journal of Hypertension, vol. 20, no. 4, pp. 392-397, 2007.

[16] M. S. Farvid, M. Jalali, F. Siassi, N. Saadat, and M. Hosseini, “The impact of vitamins and/or mineral supplementation on blood pressure in type 2 diabetes," Journal of the American College of Nutrition, vol. 23, no. 3, pp. 272-279, 2004.

[17] N. C. Ward, J. M. Hodgson, K. D. Croft, V. Burke, L. J. Beilin, and I. B. Puddey, "Effects of vitamin C and grape-seed polyphenols on blood pressure in treated hypertensive individuals: results of a randomised double blind, placebo-controlled trial," Asia Pacific Journal of Clinical Nutrition, vol. 12, supplement 18, 2003.

[18] M. Rodríguez-Morán and F. Guerrero-Romero, "Oral magnesium supplementation improves insulin sensitivity and metabolic control in type 2 diabetic subjects: a randomized double-blind controlled trial," Diabetes Care, vol. 26, no. 4, pp. 1147-1152, 2003.

[19] O. M. Alarcón, Y. Guerrero, M. Ramírez de Fernández et al., "Efecto de la suplementación con cobre sobre los valores de presión arterial en pacientes con hipertensión moderada estable," Archivos Latinoamericanos de Nutricion, vol. 53, no. 3 , pp. 271-276, 2003.

[20] B. A. Mullan, I. S. Young, H. Fee, and D. R. McCance, "Ascorbic acid reduces blood pressure and arterial stiffness in type 2 diabetes," Hypertension, vol. 40, no. 6, pp. 804-809, 2002.

[21] G. Palumbo, F. Avanzini, C. Alli et al., "Effects of vitamin E on clinic and ambulatory blood pressure in treated hypertensive patients," The American Journal of Hypertension, vol. 13, no. 5, pp. 564-567, 2000.

[22] A. Gazis, D. J. White, S. R. Page, and J. R. Cockcroft, "Effect of oral vitamin $\mathrm{E}$ ( $\alpha$-tocopherol) supplementation on vascular endothelial function in type 2 diabetes mellitus," Diabetic Medicine, vol. 16, no. 4, pp. 304-311, 1999.

[23] Y. Kawano, H. Yoshimi, H. Matsuoka, S. Takishita, and T. Omae, "Calcium supplementation in patients with essential hypertension: assessment by office, home and ambulatory blood pressure," Journal of Hypertension, vol. 16, no. 11, pp. 1693-1699, 1998.

[24] H. W. de Valk, R. Verkaaik, H. J. M. van Rijn, R. A. Geerdink, and A. Struyvenberg, "Oral magnesium supplementation in insulin-requiring Type 2 diabetic patients," Diabetic Medicine, vol. 15, no. 6, pp. 503-507, 1998.

[25] A. Siani, P. Strazzullo, and L. Russo, "Controlled trial of long term oral potassium supplements in patients with mild hypertension," The British Medical Journal, vol. 294, no. 6585, pp. 1453-1456, 1987.

[26] S. Egert, A. Bosy-Westphal, J. Seiberl et al., "Quercetin reduces systolic blood pressure and plasma oxidised lowdensity lipoprotein concentrations in overweight subjects with a high-cardiovascular disease risk phenotype: a double-blinded, placebo-controlled cross-over study," British Journal of Nutrition, vol. 102, no. 7, pp. 1065-1074, 2009.

[27] N. C. Ward, J. M. Hodgson, K. D. Croft, V. Burke, L. J. Beilin, and I. B. Puddey, "The combination of vitamin $C$ and grape-seed polyphenols increases blood pressure: a randomized, doubleblind, placebo-controlled trial," Journal of Hypertension, vol. 23, no. 2, pp. 427-434, 2005.

[28] M. Aviram and B. Fuhrman, "Wine flavonoids protect against LDL oxidation and atherosclerosis," Annals of the New York Academy of Sciences, vol. 957, pp. 146-161, 2002.

[29] J. M. Hodgson, G. F. Watts, D. A. Playford, V. Burke, and K. D. Croft, "Coenzyme Q10 improves blood pressure and glycaemic control: a controlled trial in subjects with type 2 diabetes," European Journal of Clinical Nutrition, vol. 56, no. 11, pp. 1137$1142,2002$.

[30] B. E. Burke, R. Neuenschwander, and R. D. Olson, "Randomized, double-blind, placebo-controlled trial of coenzyme Q10 in isolated systolic hypertension," Southern Medical Journal, vol. 94, no. 11, pp. 1112-1117, 2001.

[31] E. H. Lee, J. E. Park, Y. J. Choi, K. B. Huh, and W. Y. Kim, "A randomized study to establish the effects of spirulina in type 2 diabetes mellitus patients," Nutrition Research and Practice, vol. 2, no. 4, pp. 295-300, 2008.

[32] P. V. Torres-Duran, A. Ferreira-Hermosillo, and M. A. JuarezOropeza, "Antihyperlipemic and antihypertensive effects of Spirulina maxima in an open sample of mexican population: a preliminary report," Lipids in Health and Disease, vol. 6, article 33, 2007.

[33] S. G. West, A. Likos-Krick, P. Brown, and F. Mariotti, "Oral Larginine improves hemodynamic response to stress and reduces plasma homocysteine in hypercholesterolemic men," Journal of Nutrition, vol. 135, no. 2, pp. 212-217, 2005.

[34] G. Duda, J. Suliburska, and D. Pupek-Musialik, "Effects of short-term garlic supplementation on lipid metabolism and antioxidant status in hypertensive adults," Pharmacological Reports, vol. 60, no. 2, pp. 163-170, 2008.

[35] S. Mizushima, K. Ohshige, J. Watanabe et al., "Randomized controlled trial of sour milk on blood pressure in borderline 
hypertensive men," The American Journal of Hypertension, vol. 17, no. 8, pp. 701-706, 2004.

[36] Y. K. Park, J. S. Kim, and M. H. Kang, "Concord grape juice supplementation reduces blood pressure in Korean hypertensive men: double-blind, placebo controlled intervention trial," BioFactors, vol. 22, no. 1-4, pp. 145-147, 2004.

[37] V. Burke, J. M. Hodgson, L. J. Beilin, N. Giangiulioi, P. Rogers, and I. B. Puddey, "Dietary protein and soluble fiber reduce ambulatory blood pressure in treated hypertensives," Hypertension, vol. 38, no. 4, pp. 821-826, 2001.

[38] V. Vuksan, D. Whitham, J. L. Sievenpiper et al., "Supplementation of conventional therapy with the novel grain salba (Salvia hispanica L.) improves major and emerging cardiovascular risk factors in type 2 diabetes: results of a randomized controlled trial," Diabetes Care, vol. 30, no. 11, pp. 2804-2810, 2007.

[39] G. K. Paschos, F. Magkos, D. B. Panagiotakos, V. Votteas, and A. Zampelas, "Dietary supplementation with flaxseed oil lowers blood pressure in dyslipidaemic patients," European Journal of Clinical Nutrition, vol. 61, no. 10, pp. 1201-1206, 2007.

[40] S. Wang, A.-Q. Ma, S.-W. Song, Q.-H. Quan, X.-F. Zhao, and X.-H. Zheng, "Fish oil supplementation improves large arterial elasticity in overweight hypertensive patients," European Journal of Clinical Nutrition, vol. 62, no. 12, pp. 1426-1431, 2008.

[41] T. Iwata, T. Kamegai, Y. Yamauchi-Sato et al., "Safety of dietary conjugated linoleic acid (CLA) in a 12-weeks trial in healthy overweight Japanese male volunteers," Journal of Oleo Science, vol. 56, no. 10, pp. 517-525, 2007.

[42] M. Svensson, J. H. Christensen, J. Sølling, and E. B. Schmidt, "The effect of n-3 fatty acids on plasma lipids and lipoproteins and blood pressure in patients with CRF," The American Journal of Kidney Diseases, vol. 44, no. 1, pp. 77-83, 2004.

[43] D. J. A. Jenkins, C. W. C. Kendall, A. Marchie et al., "Dose response of almonds on coronary heart disease risk factors: blood lipids, oxidized low-density lipoproteins, lipoprotein(a), homocysteine, and pulmonary nitric oxide: a randomized, controlled, crossover trial," Circulation, vol.106, no. 11, pp. 13271332, 2002.

[44] L. Agerholm-Larsen, A. Raben, N. Haulrik, A. S. Hansen, M. Manders, and A. Astrup, "Effect of 8 week intake of probiotic milk products on risk factors for cardiovascular diseases," European Journal of Clinical Nutrition, vol. 54, no. 4, pp. 288297, 2000

[45] M. Shargorodsky, O. Debby, Z. Matas, and R. Zimlichman, "Effect of long-term treatment with antioxidants (vitamin C, vitamin E, coenzyme Q10 and selenium) on arterial compliance, humoral factors and inflammatory markers in patients with multiple cardiovascular risk factors," Nutrition and Metabolism, vol. 7, article 55, 2010.

[46] Y. Minamiyama, S. Takemura, Y. Bito et al., "Supplementation of $\alpha$-tocopherol improves cardiovascular risk factors via the insulin signalling pathway and reduction of mitochondrial reactive oxygen species in type II diabetic rats," Free Radical Research, vol. 42, no. 3, pp. 261-271, 2008.

[47] K. K. Griendling and G. A. FitzGerald, "Oxidative Stress and Cardiovascular Injury. Part II: animal and Human Studies," Circulation, vol. 108, no. 17, pp. 2034-2040, 2003.

[48] S. Devaraj, A. Harris, and I. Jialal, "Modulation of monocytemacrophage function with $\alpha$-tocopherol: implications for atherosclerosis," Nutrition Reviews, vol. 60, no. 1, pp. 8-14, 2002.

[49] M. G. Traber and J. F. Stevens, "Vitamins C and E: beneficial effects from a mechanistic perspective," Free Radical Biology and Medicine, vol. 51, no. 5, pp. 1000-1013, 2011.
[50] M. D. Fotherby, J. C. Williams, L. A. Forster, P. Craner, and G. A. Ferns, "Effect of vitamin $\mathrm{C}$ on ambulatory blood pressure and plasma lipids in older persons," Journal of Hypertension, vol. 18, no. 4, pp. 411-415, 2000.

[51] S. J. Duffy, N. Gokce, M. Holbrook et al., "Treatment of hypertension with ascorbic acid," The Lancet, vol. 354, no. 9195, pp. 2048-2049, 1999.

[52] J. Lykkesfeldt and H. E. Poulsen, "Is vitamin C supplementation beneficial? Lessons learned from randomised controlled trials," The British Journal of Nutrition, vol. 103, no. 9, pp. 1251-1259, 2010.

[53] N. Gokce, J. F. Keaney Jr., B. Frei et al., "Long-term ascorbic acid administration reverses endothelial vasomotor dysfunction in patients with coronary artery disease," Circulation, vol. 99, no. 25, pp. 3234-3240, 1999.

[54] P. M. Kris-Etherton, A. H. Lichtenstein, B. V. Howard, D. Steinberg, and J. L. Witztum, "Antioxidant vitamin supplements and cardiovascular disease," Circulation, vol. 110, no. 5, pp. 637641, 2004.

[55] E. R. Miller, L. A. Lawrence, O. A. Levander, and D. M. Levine, "The effect of antioxidant vitamin supplementation on traditional cardiovascular risk factors," Journal of Cardiovascular Risk, vol. 4, no. 1, pp. 19-24, 1997.

[56] H. Han-Yao, "A factorial trial of vitamin C and vitamin E supplementation: no effect on blood pressure, but synergy in lowering total and LDL cholesterol," in Proceedings of the 38th Annual Conference on Cardiovascular Disease Epidemiology and prevention, 1998.

[57] R. S. Gupta, E. S. Gupta, B. K. Dhakal, A. R. Thakur, and J. Ahnn, "Vitamin C and Vitamin E protect the rat testes from cadmiuminduced reactive oxygen species," Molecules and Cells, vol. 17, no. 1, pp. 132-139, 2004.

[58] H. Cai and D. G. Harrison, "Endothelial dysfunction in cardiovascular diseases: the role of oxidant stress," Circulation Research, vol. 87, no. 10, pp. 840-844, 2000.

[59] G. Zalba, G. San José, M. U. Moreno et al., "Oxidative stress in arterial hypertension: role of $\mathrm{NAD}(\mathrm{P}) \mathrm{H}$ oxidase," Hypertension, vol. 38, no. 6, pp. 1395-13959, 2001.

[60] M. F. Holick, "Vitamin D: important for prevention of osteoporosis, cardiovascular heart disease, type 1 diabetes, autoimmune diseases, and some cancers," Southern Medical Journal, vol. 98, no. 10, pp. 1024-1027, 2005.

[61] M. Pfeifer, B. Begerow, H. W. Minne, D. Nachtigall, and C. Hansen, "Effects of a short-term vitamin D3 and calcium supplementation on blood pressure and parathyroid hormone levels in elderly women," Journal of Clinical Endocrinology and Metabolism, vol. 86, no. 4, pp. 1633-1637, 2001.

[62] D. Zehnder, R. Bland, E. A. Walker et al., "Expression of 25-hydroxyvitamin D3-1 $\alpha$-hydroxylase in the human kidney," Journal of the American Society of Nephrology, vol. 10, no. 12, pp. 2465-2473, 1999.

[63] C. A. Papaharalambus and K. K. Griendling, "Basic mechanisms of oxidative stress and reactive oxygen species in cardiovascular injury," Trends in Cardiovascular Medicine, vol. 17, no. 2, pp. 48-54, 2007.

[64] T. J. Kizhakekuttu and M. E. Widlansky, "Natural antioxidants and hypertension: promise and challenges," Cardiovascular Therapeutics, vol. 28, no. 4, pp. e20-e32, 2010.

[65] I. C. W. Arts, D. R. Jacobs Jr., L. J. Harnack, M. Gross, and A. R. Folsom, "Dietary catechins in relation to coronary heart disease death among postmenopausal women," Epidemiology, vol. 12, no. 6 , pp. 668-675, 2001. 
[66] I. C. Arts and P. C. Hollman, "Polyphenols and disease risk in epidemiologic studies," The American Journal of Clinical Nutrition, vol. 81, no. 1, pp. 317S-325S, 2005.

[67] U. Peters, C. Poole, and L. Arab, "Does tea affect cardiovascular disease? A meta-analysis," The American Journal of Epidemiology, vol. 154, no. 6, pp. 495-503, 2001.

[68] L. A. Bazzano, J. He, L. G. Ogden et al., "Fruit and vegetable intake and risk of cardiovascular disease in US adults: the first National Health and Nutrition Examination Survey Epidemiologic Follow-up Study," The American Journal of Clinical Nutrition, vol. 76, no. 1, pp. 93-99, 2002.

[69] S. B. Lotito and B. Frei, "Consumption of flavonoid-rich foods and increased plasma antioxidant capacity in humans: cause, consequence, or epiphenomenon?" Free Radical Biology and Medicine, vol. 41, no. 12, pp. 1727-1746, 2006.

[70] P. J. Mink, C. G. Scrafford, L. M. Barraj et al., "Flavonoid intake and cardiovascular disease mortality: a prospective study in postmenopausal women," The American Journal of Clinical Nutrition, vol. 85, no. 3, pp. 895-909, 2007.

[71] A. Cherubini, C. Ruggiero, C. Morand et al., "Dietary antioxidants as potential pharmacological agents for ischemic stroke," Current Medicinal Chemistry, vol. 15, no. 12, pp. 1236-1248, 2008.

[72] K. B. Pandey and S. I. Rizvi, "Plant polyphenols as dietary antioxidants in human health and disease," Oxidative Medicine and Cellular Longevity, vol. 2, no. 5, pp. 270-278, 2009.

[73] T. Baster and C. Baster-Brooks, "Exercise and hypertension," Australian Family Physician, vol. 34, no. 6, pp. 419-424, 2005.

[74] K. Overvad, B. Diamant, L. Holm, G. Hølmer, S. A. Mortensen, and S. Stender, "Coenzyme Q10 in health and disease," European Journal of Clinical Nutrition, vol. 53, no. 10, pp. 764-770, 1999.

[75] T. Wallerath, G. Deckert, T. Ternes et al., "Resveratrol, a polyphenolic phytoalexin present in red wine, enhances expression and activity of endothelial nitric oxide synthase," Circulation, vol. 106, no. 13, pp. 1652-1658, 2002.

[76] C. Heiss, A. Dejam, P. Kleinbongard, T. Schewe, H. Sies, and M. Kelm, "Vascular effects of cocoa rich in Flavan-3-ols," Journal of the American Medical Association, vol. 290, no. 8, pp. 1030-1031, 2003.

[77] E. Anter, S. R. Thomas, E. Schulz, O. M. Shapira, J. A. Vita, and J. F. Keaney Jr., "Activation of endothelial nitric-oxide synthase by the p38 MAPK in response to black tea polyphenols," Journal of Biological Chemistry, vol. 279, no. 45, pp. 46637-46643, 2004.

[78] J. F. Leikert, T. R. Räthel, P. Wohlfart, V. Cheynier, A. M. Vollmar, and V. M. Dirsch, "Red wine polyphenols enhance endothelial nitric oxide synthase expression and subsequent nitric oxide release from endothelial cells," Circulation, vol. 106, no. 13, pp. 1614-1617, 2002.

[79] C. A. Schmitt and V. M. Dirsch, "Modulation of endothelial nitric oxide by plant-derived products," Nitric Oxide, vol. 21, no. 2, pp. 77-91, 2009.

[80] J. C. Stoclet, T. Chataigneau, M. Ndiaye et al., "Vascular protection by dietary polyphenols," European Journal of Pharmacology, vol. 500, no. 1-3, pp. 299-313, 2004.

[81] M. Aviram and L. Dornfeld, "Pomegranate juice consumption inhibits serum angiotensin converting enzyme activity and reduces systolic blood pressure," Atherosclerosis, vol. 158, no. 1, pp. 195-198, 2001.

[82] Y. J. Jeong, Y. J. Choi, H. M. Kwon et al., "Differential inhibition of oxidized LDL-induced apoptosis in human endothelial cells treated with different flavonoids," The British Journal of Nutrition, vol. 93, no. 5, pp. 581-591, 2005.
[83] B. Fuhrman, N. Volkova, R. Coleman, and M. Aviram, "Grape powder polyphenols attenuate atherosclerosis development in apolipoprotein E deficient (E0) mice and reduce macrophage atherogenicity," Journal of Nutrition, vol. 135, no. 4, pp. 722-728, 2005.

[84] A. Ludwig, M. Lorenz, N. Grimbo et al., "The tea flavonoid epigallocatechin-3-gallate reduces cytokine-induced VCAM1 expression and monocyte adhesion to endothelial cells," Biochemical and Biophysical Research Communications, vol. 316, no. 3, pp. 659-665, 2004.

[85] J. M. Hodgson and K. D. Croft, "Dietary flavonoids: effects on endothelial function and blood pressure," Journal of the Science of Food and Agriculture, vol. 86, no. 15, pp. 2492-2498, 2006.

[86] Y. Guan, H. Y. Zhao, X. F. Ding, and Y. Y. Zhu, "Analysis of the contents of elements in spinrulina from different producing areas," Guang Pu Xue Yu Guang Pu Fen Xi, vol. 27, no. 5, pp. 1029-1031, 2007.

[87] J. P. Lekakis, S. Papathanassiou, T. G. Papaioannou et al., "Oral $\mathrm{L}$-arginine improves endothelial dysfunction in patients with essential hypertension," International Journal of Cardiology, vol. 86, no. 2-3, pp. 317-323, 2002.

[88] Z. Khan, P. Bhadouria, and P. S. Bisen, "Nutritional and therapeutic potential of Spirulina," Current Pharmaceutical Biotechnology, vol. 6, no. 5, pp. 373-379, 2005.

[89] D. Mascher, M. C. Paredes-Carbajal, P. V. Torres-Durán, J. Zamora-González, J. C. Díaz-Zagoya, and M. A. JuárezOropeza, "Ethanolic extract of Spirulina maxima alters the vasomotor reactivity of aortic rings from obese rats," Archives of Medical Research, vol. 37, no. 1, pp. 50-57, 2006.

[90] P. Parikh, U. Mani, and U. Iyer, "Role of Spirulina in the control of glycemia and lipidemia in type 2 diabetes mellitus," Journal of Medicinal Food, vol. 4, no. 4, pp. 193-199, 2001.

[91] G. Hsiao, P. O. H. Chou, M. Y. Shen, D. S. Chou, C. H. Lin, and J. R. Sheu, "C-phycocyanin, a very potent and novel platelet aggregation inhibitor from Spirulina platensis," Journal of Agricultural and Food Chemistry, vol. 53, no. 20, pp. 77347740, 2005.

[92] V. Martina, A. Masha, V. R. Gigliardi et al., "Long-term nacetylcysteine and l-arginine administration reduces endothelial activation and systolic blood pressure in hypertensive patients with type 2 diabetes," Diabetes Care, vol. 31, no. 5, pp. 940-944, 2008.

[93] K. Rytlewski, R. Olszanecki, R. Korbut, and Z. Zdebski, "Effects of prolonged oral supplementation with L-arginine on blood pressure and nitric oxide synthesis in preeclampsia," European Journal of Clinical Investigation, vol. 35, no. 1, pp. 32-37, 2005.

[94] Y. Higashi and M. Yoshizumi, "Exercise and endothelial function: role of endothelium-derived nitric oxide and oxidative stress in healthy subjects and hypertensive patients," Pharmacology and Therapeutics, vol. 102, no. 1, pp. 87-96, 2004.

[95] V. Dhawan and S. Jain, "Effect of garlic supplementation on oxidized low density lipoproteins and lipid peroxidation in patients of essential hypertension," Molecular and Cellular Biochemistry, vol. 266, no. 1-2, pp. 109-115, 2004.

[96] I. Durak, M. Kavutcu, B. Aytaç et al., "Effects of garlic extract consumption on blood lipid and oxidant/antioxidant parameters in humans with high blood cholesterol," Journal of Nutritional Biochemistry, vol. 15, no. 6, pp. 373-377, 2004.

[97] L. D. Brace, "Cardiovascular benefits of garlic (Allium sativum L)," The Journal of Cardiovascular Nursing, vol. 16, no. 4, pp. 3349, 2002. 
[98] R. Gebhardt and H. Beck, "Differential inhibitory effects of garlic-derived organosulfur compounds on cholesterol biosynthesis in primary rat hepatocyte cultures," Lipids, vol. 31, no. 12, pp. 1269-1276, 1996.

[99] S. Warshafsky, R. S. Kamer, and S. L. Sivak, "Effect of garlic on total serum cholesterol: a meta-analysis," Annals of Internal Medicine, vol. 119, no. 7 I, pp. 599-605, 1993.

[100] L. H. Opie and S. Lecour, "The red wine hypothesis: from concepts to protective signalling molecules," European Heart Journal, vol. 28, no. 14, pp. 1683-1693, 2007.

[101] M. Diebolt, B. Bucher, and R. Andriantsitohaina, "Wine polyphenols decrease blood pressure, improve $\mathrm{NO}$ vasodilatation, and induce gene expression," Hypertension, vol. 38, no. 2, pp. 159-165, 2001.

[102] Y. Nakamura, N. Yamamoto, K. Sakai, and T. Takano, "Antihypertensive effect of sour milk and peptides isolated from it that are inhibitors to angiotensin I-converting enzyme," Journal of Dairy Science, vol. 78, no. 6, pp. 1253-1257, 1995.

[103] M. Feinleib, C. Lenfant, and S. A. Miller, "Hypertension and calcium," Science, vol. 226, no. 4673, pp. 384-389, 1984.

[104] D. Grassi, S. Necozione, C. Lippi et al., "Cocoa reduces blood pressure and insulin resistance and improves endotheliumdependent vasodilation in hypertensives," Hypertension, vol. 46, no. 2, pp. 398-405, 2005.

[105] A. Figueroa, M. A. Sanchez-Gonzalez, A. Wong, and B. H. Arjmandi, "Effects of dark chocolate on blood pressure in patients with hypertension," The American Journl of Hypertension, vol. 25, no. 6, pp. 649-643, 2012.

[106] M. H. Williams, "Dietary supplements and sports performance: introduction and vitamins," Journal of the International Society of Sports Nutrition, vol. 1, no. 2, pp. 1-6, 2004.

[107] J. Sundgot-Borgen, B. Berglund, and M. K. Torstveit, "Nutritional supplements in Norwegian elite athletes: impact of international ranking and advisors," Scandinavian Journal of Medicine and Science in Sports, vol. 13, no. 2, pp. 138-144, 2003. 


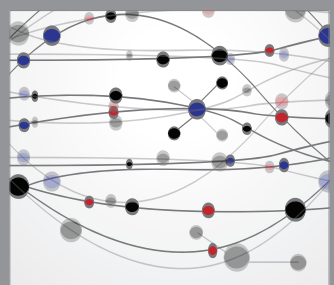

The Scientific World Journal
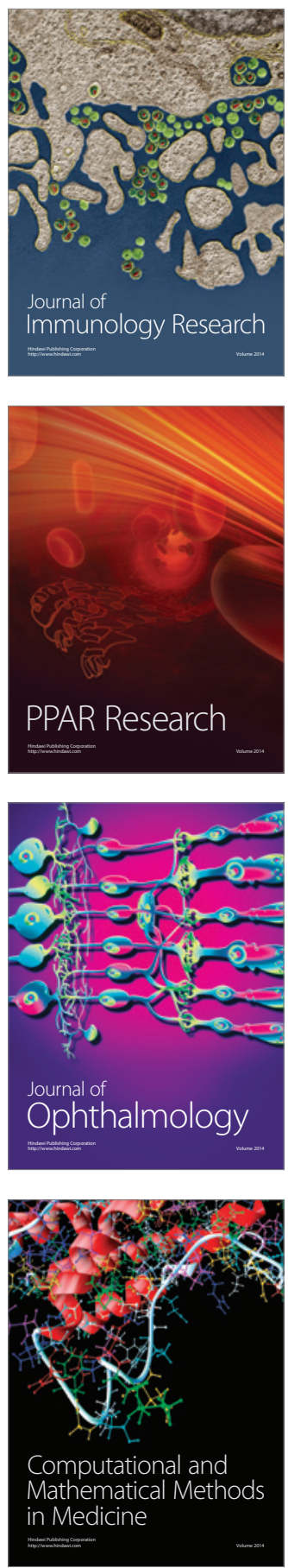

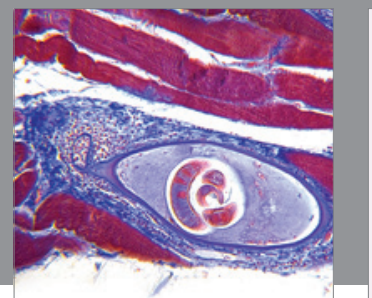

Gastroenterology

Research and Practice
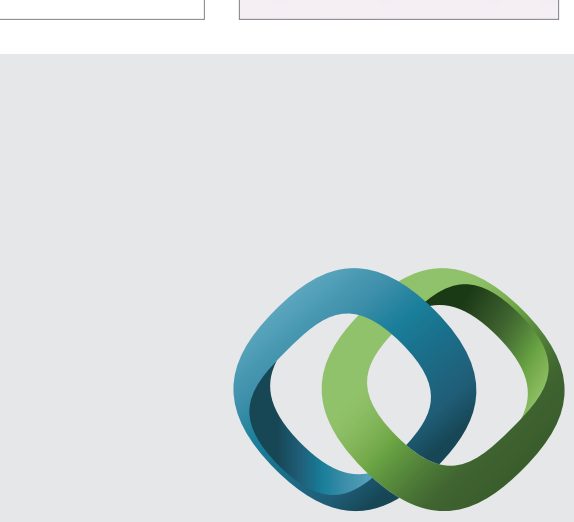

\section{Hindawi}

Submit your manuscripts at

http://www.hindawi.com
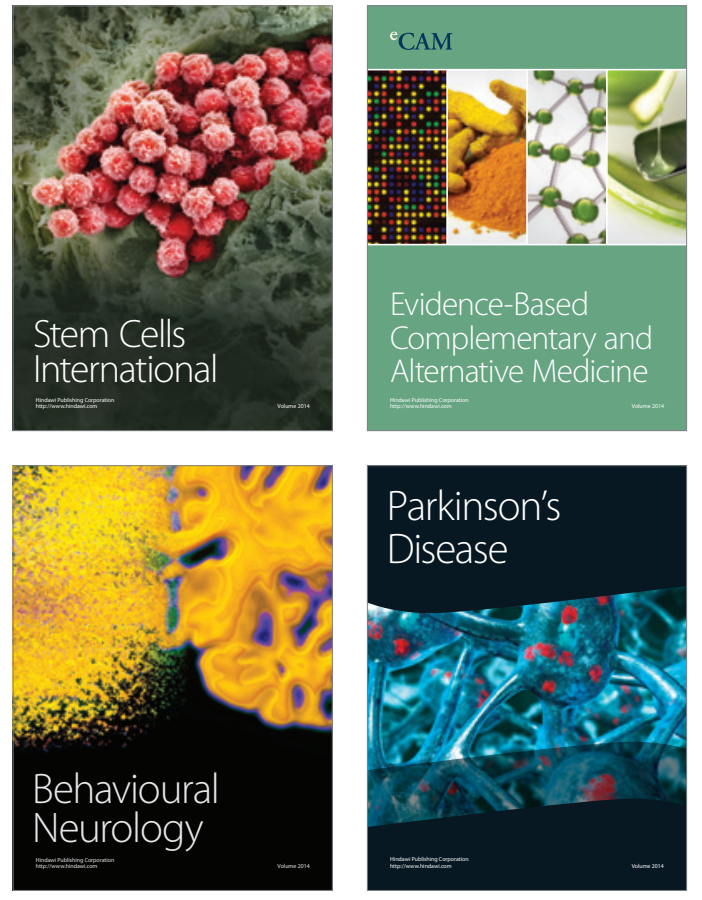
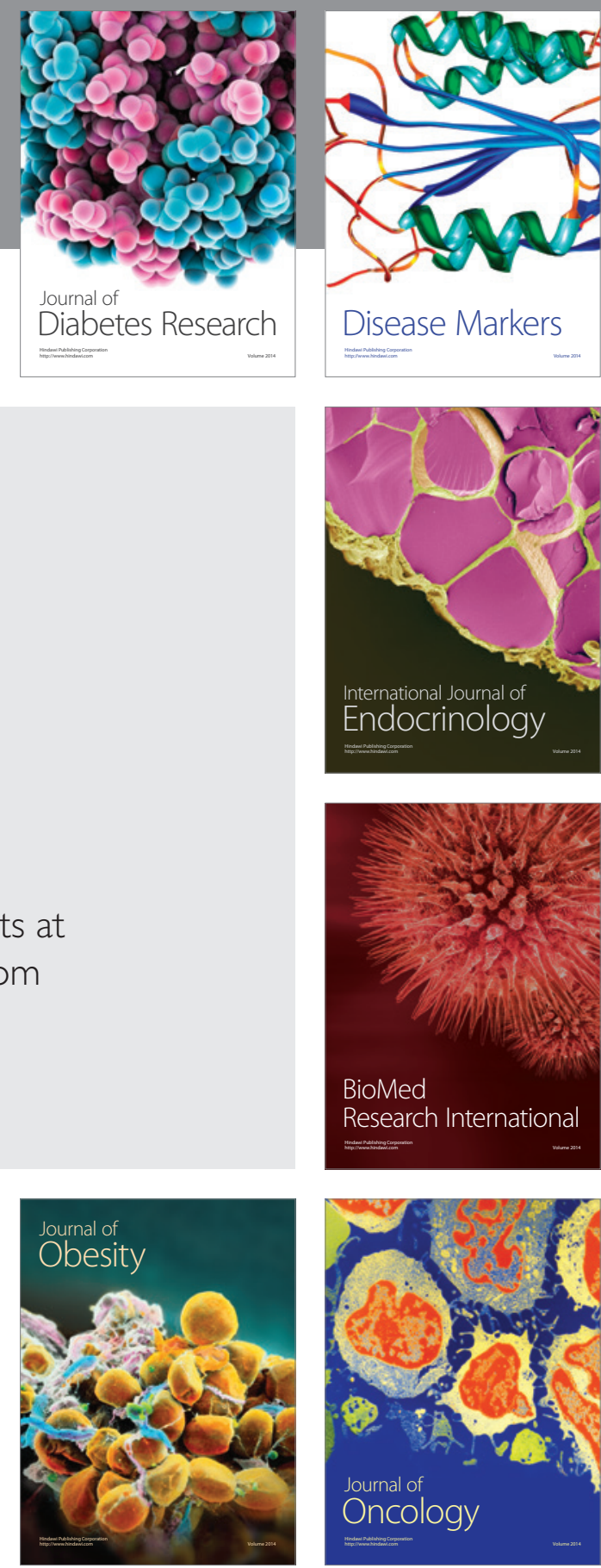

Disease Markers
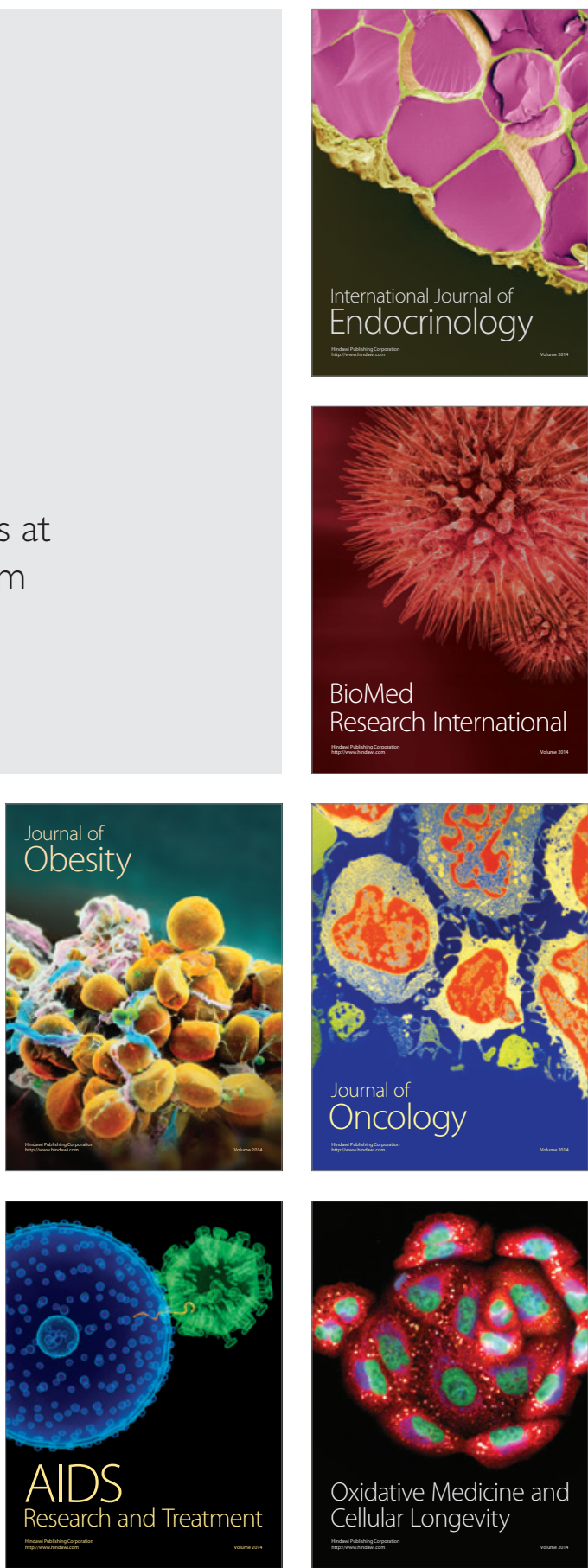